\title{
Assessment of remote sensing and GIS application in identification of land suitability for agroforestry: A case study of Samastipur, Bihar, India
}

\author{
Firoz Ahmad ${ }^{1 *}$, Md Meraj Uddin², Laxmi Goparaju ${ }^{1}$ \\ ${ }^{l}$ Vindhyan Ecology and Natural History Foundation, Mirzapur, Uttar Pradesh, India. \\ ${ }^{2}$ University Department of Mathematics, MCA, Ranchi University, Ranchi, Jharkhand, India \\ ${ }^{*}$ Corresponding author: adfiroz@yahoo.com
}

Received: $2^{\text {nd }}$ July, 2018

Accepted: $5^{\text {th }}$ November, 2018

\begin{abstract}
Agroforestry provides the foundation for climate-smart agriculture to withstand the extreme weather events. The aim of the present study was to identify the land of Samastipur, Bihar, India for agroforestry, based on GIS modeling concept utilizing various ancillary (soil fertility) and satellite data (DEM, wetness, NDVI and LULC) sets. This was achieved by integrating various thematic layers logically in GIS domain. Agroforestry suitability maps were generated for the Samastipur district of Bihar, India which showed $48.22 \%$ as very high suitable, 22.83 $\%$ as high suitable, $23.32 \%$ as moderate suitable and $5.63 \%$ as low suitable. The cross evaluation of agroforestry suitability with LULC categories revealed that the $86.4 \%$ (agriculture) and $30.2 \%$ (open area) of land fall into a very high agroforestry suitability category which provides the huge opportunity to harness agroforestry practices if utilized scientifically. Such analysis/results will certainly assist agroforestry policymakers and planner in the state of Bihar, India to implement and extend it to new areas. The potentiality of Remote Sensing and GIS can be exploited in accessing suitable land for agroforestry which will significantly help to rural poor people/farmers in ensuring food and ecological security, resilience in livelihoods.
\end{abstract}

Key words: Agroforestry; Remote Sensing; GIS; Land suitability; Temperature anomalies

\section{Introduction}

In recent years the potential impacts of climate change have been significantly discussed by the researchers/scientists around the world. The study conducted in India on climate change revealed that there is the occurrence of extreme events in the future (Sinha Ray \& De (2003), increase in temperature (Lal et al., 1995), abrupt rainfall pattern (Lal, 2003; Goswami et al., 2006; Dash et al., 2007) and increase in drought (Ramanathan et al., 2005). The climate change induced events had significantly reduced the food grain production of the agriculture crops (Zhou et al. 2017). Kharif and rabi are the two cropping pattern season which are adopted in many Asian monsoon countries. The cropping season of kharif starts from July -October during the south-west monsoon and the rabi cropping season is from October-March (winter). The temperature increase during these seasons creates soil water deficit due to mutual interaction in changing climate impact (Hatfield $\&$ Prueger, 2015) thus significantly reduce the production of various rabi and kharif crops (Zhao et al. 2017) .

Agroforestry maintains permanent tree structure and provides diversified ecological niches with temporal and spatial management options which have the capacity to tolerate the 
climate variability, to build resilience (Torquebiau 2013) and thus support significantly to climate smart agriculture (Newaj et al. 2015).

The human populations are rising sharply whereas land resources are limited; the demands for food, fuel, fodder are increasing day by day. Therefore new policy driven options are required to address the emerging challenges of attaining improved food security in agriculture sector (Glantz 2009).

The agroforestry system and its potentiality are well proved to provide the sustainability in climatic change scenario, which can withstand the severe weather events such as floods, droughts, cyclones and hurricanes (NAP, 2014) by supporting the food security from the local to global level.

Agroforestry is defined as "a collective name for land-use systems and technologies, where the woody perennials (trees, shrubs, palms, bamboos, etc.) are deliberately applied to the same land management unit as agricultural crops and/or animals, either in some form of spatial arrangement or temporal sequence. In agroforestry systems there are both ecological and economical interactions between the different components" (ICRAF, 1993).

Scientific evaluation of land is a prerequisite for better management of part of smart planning for the benefit of human society in both developing and developed countries.

The progress in Remote Sensing, GIS and computer science including various high end software and hardware have facilitated the process for implementation of its principles and attracted the scientists/researchers globally in diversified applications including Agroforestry mapping (Zomer et al. 2009; Chen et al. 2016).

Why this study is important?

1. It utilized diversified data sets using the GIS modeling concept.

2. Most of the states of India including Bihar are suffering from crop failure, poverty and severe weather events (Miyan 2015) therefore agroforestry policy need to be prioritized and the scientific evaluation of lands are needed to be expanded in new areas.

3. Policy maker of state agencies working in agroforestry/forestry/agriculture/rural

development need such data to understand and implement at various level of project planning/management/execution.

4. The maps, result and analysis using advance technology such as Remote Sensing/GIS are still in the budding stage thus there is a need to exploit such technology with full potential in the field of agroforestry (Ellis et al. 2000).

Therefore, the scientific/logical analysis of land for agroforestry suitability is a need of hour and can be logically evaluated using geospatial technology (Ellis et al. 2004; Ahmad et al. 2017a). It has the great advantage over the traditional/conventional approaches because it is cost effective and efficient.

Few researchers and scientists have evaluated land in GIS Domain for agroforestry (Ritung et al. 2007; Reisner et al. 2007). The Remote Sensing data and GIS modeling concept were successfully used for Agroforestry suitability mapping (Ahmad et al. 2018a; Ahmad et al. 2018b)

The present study aims at applying Remote Sensing data and GIS towards visualizing the spatial features of land, soil, and topographical data to reveal the trends and their association and to achieve an agroforestry suitability mapping of Samastipur district of Bihar, India. The agroforestry map was further evaluated based on the various land use/ land cover categories. The temperature anomalies predictive model data for the year 2050 was used to understand the future temperature change impact on kharif and rabi crops. 


\section{Materials and Methods}

\section{The Study area}

Samastipur is one of the districts of Bihar separated on 14 November 1972 from the district of Darbhanga which is spread over an area of 2904 sq. kms. The major rivers are Burhi Gandak and the Ganga which constitute the principal drainage in the area whereas Baya, the Bagmati and the Balan are relatively smaller streams. The district falls in the monsoon tropical zone and is characterized by semi-arid to subtropical climate. The temperature varies from $6{ }^{\circ} \mathrm{C}$ in winter to $45^{\circ} \mathrm{C}$ in summer. The annual rainfall varies from $1100 \mathrm{~mm}$. to 1200 $\mathrm{mm}$. The soil is light to clay in texture and supports main crops such as rice, maize, wheat, pulses, oilseeds, tobacco, sugarcane, spices and vegetables. The major horticulture crops are mango (Mangifera indica), guava (Psidium guajava), banana (Musa genus), lemon (Citrus limon) and litchi (Litchi chinensis). The area is largely supported by fast growing tree species such as Deshi siris (Albizia lebbeck), Shisham (Dalbergia sissoo), Gamhar (Gmelina arborea), Deshi semal (Bombax ceiba), Green semal (Ceiba pentendra).The cattle rearing such as buffaloes, goats, sheep and pig are quit common whereas poultry are significantly supported by integrating farming.

\section{Data acquisition and processing}

The various soil maps (http://www.iiss. nic.in/mapd_5.htm) such as nitrogen, phosphorus, potassium, organic carbon and $\mathrm{pH}$ status of Samastipur which were prepared by Indian Institute of soil science, Bhopal were used in this study for determining the soil fertility status.

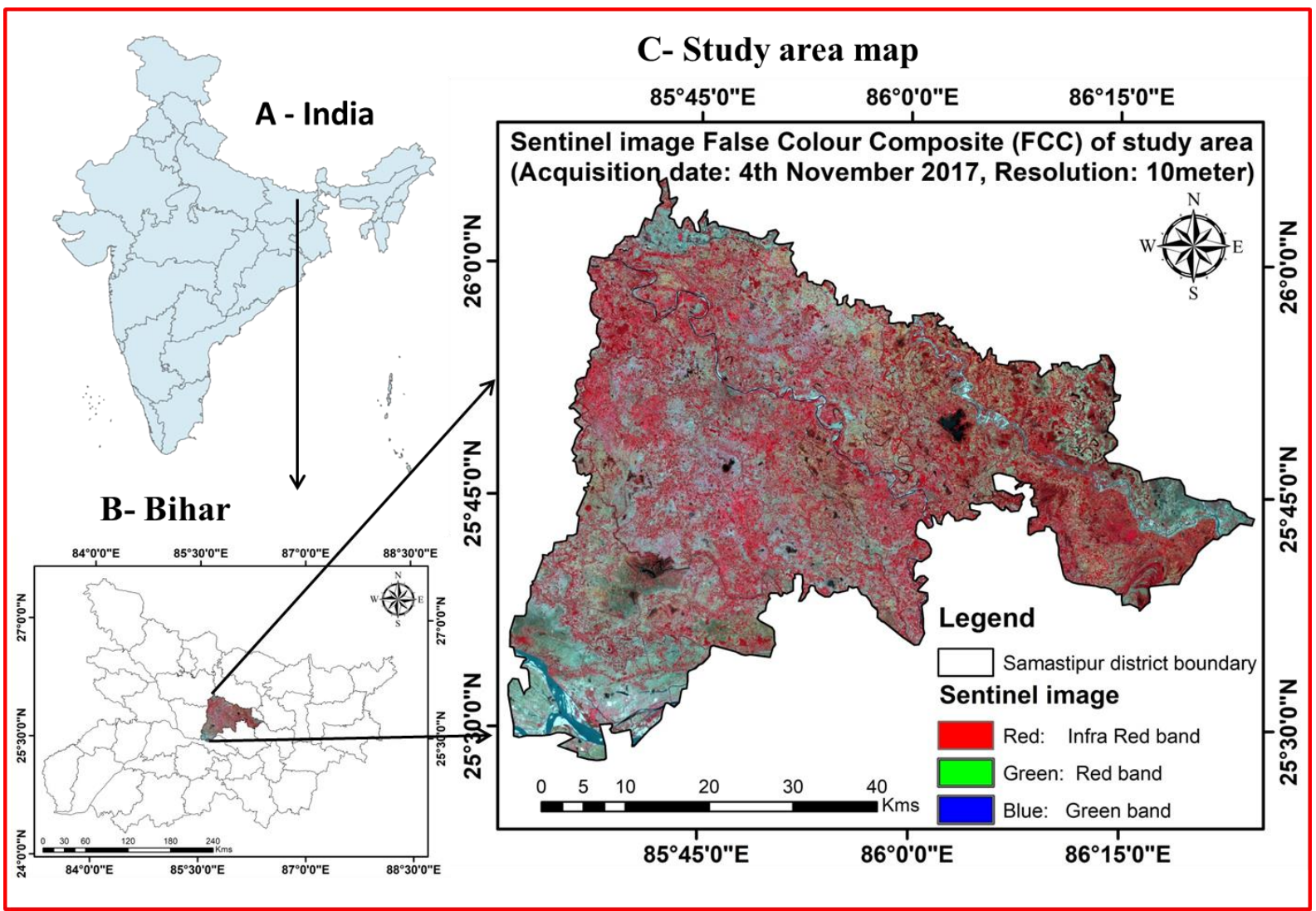

Fig.1. Location of the study area with the SETINEL super-spectral imaging for land of Samastipur district 
The Sentinel data with acquisition date $4^{\text {th }}$ November 2017 having 10 meter resolution is used to classify various Land use/ land cover (LULC) classes. The Landsat- 8 satellite data with acquisition date $21^{\text {st }}$ November 2017 was used to determine the wetness map of the study area. The ASTER DEM (30 meter resolution) is used to determining the slope percent. We have used the temperature anomalies (climate change scenario, RCP 6) data for the year 2050 (NCAR GIS Program. 2012) for determining the temperature in kharif and rabi season. Representative Concentration Pathways (RCPs), which provide concentrations of atmospheric greenhouse gas (GHG) and the trajectory that, is taken over time to reach those concentrations (Inman, 2011). RCPs are four greenhouse gas concentration (RCP2.6,
RCP4.5, RCP6, and RCP8.5) trajectories adopted by the IPCC for its fifth Assessment Report (AR5) in 2014. The ERDAS Imagine and ARC/GIS Software are significantly utilized for achieving our objectives.

\section{Soil fertility status map}

The different soil related maps were first rectified and all soil polygon categories were brought into GIS domain (Ahmad et al. 2017a). The soil fertility status map (Figure 3) was generated by integrating soil nitrogen map, soil phosphorus map, soil potassium map, soil organic carbon map and soil pH map in GIS modeling concept assigning equal weight and various rank (Table 1) to each theme (Figure 2).

Ahmad et al. (2017b) did the similar soil map integration in GIS domain by assigning

Tab.1 Weight factors/ranks for determining soil fertility status

\begin{tabular}{lllll}
\hline Soil map & Weights $\%$ & Value $/$ Description & Ranks & Suitability \\
\hline Nitrogen & $\mathbf{2 0}$ & $500-250 \mathrm{~kg} / \mathrm{ha}$ & 2 & Medium \\
& & $<250 \mathrm{~kg} / \mathrm{ha}$ & 1 & Low \\
\hline Phosphorus & $\mathbf{2 0}$ & $>22 \mathrm{~kg} / \mathrm{ha}$ & 3 & High \\
& & $22-11 \mathrm{~kg} / \mathrm{ha}$ & 2 & Medium \\
& & $<11 \mathrm{~kg} / \mathrm{ha}$ & 1 & Low \\
\hline Potassium & $\mathbf{2 0}$ & $249-104 \mathrm{~kg} / \mathrm{ha}$ & 3 & High \\
& & $<104 \mathrm{~kg} / \mathrm{ha}$ & 2 & Medium \\
& $\mathbf{2 0}$ & $>0.75$ & 1 & Low \\
\hline Organic carbon $(\%)$ & & $0.75-.50$ & 3 & High \\
& & $<0.50$ & 2 & Medium \\
& $\mathbf{2 0}$ & $8.5-6.5$ & 1 & Low \\
\hline $\mathrm{pH}$ & & $<6.5,>8.5$ & 3 & High \\
& & 2 & Medium \\
\hline
\end{tabular}

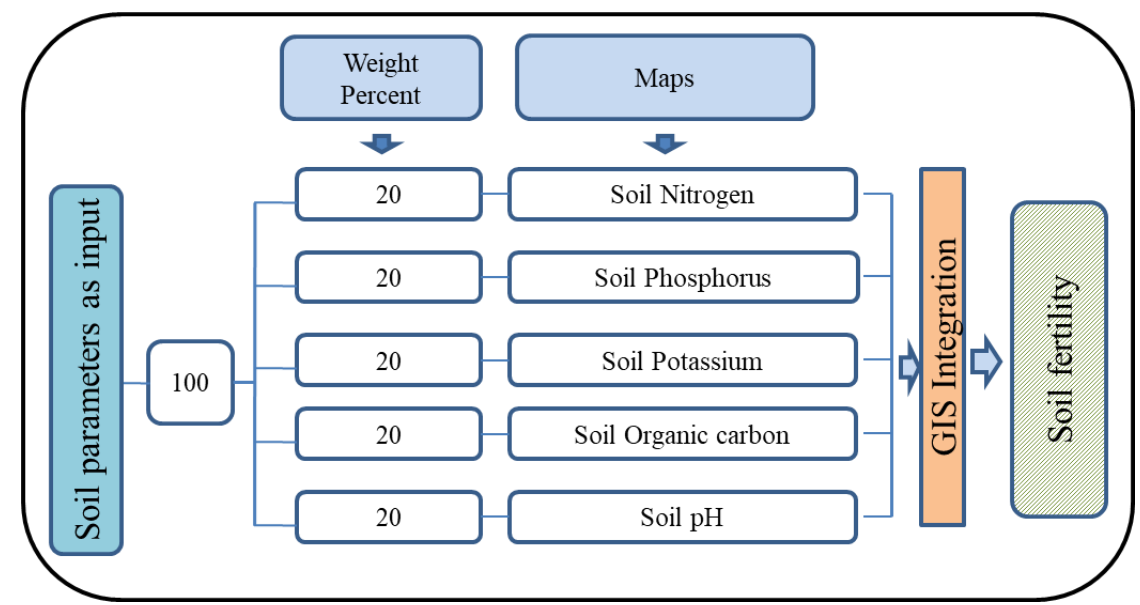

Fig.2. GIS Integration and modeling for generating soil fertility status of land 


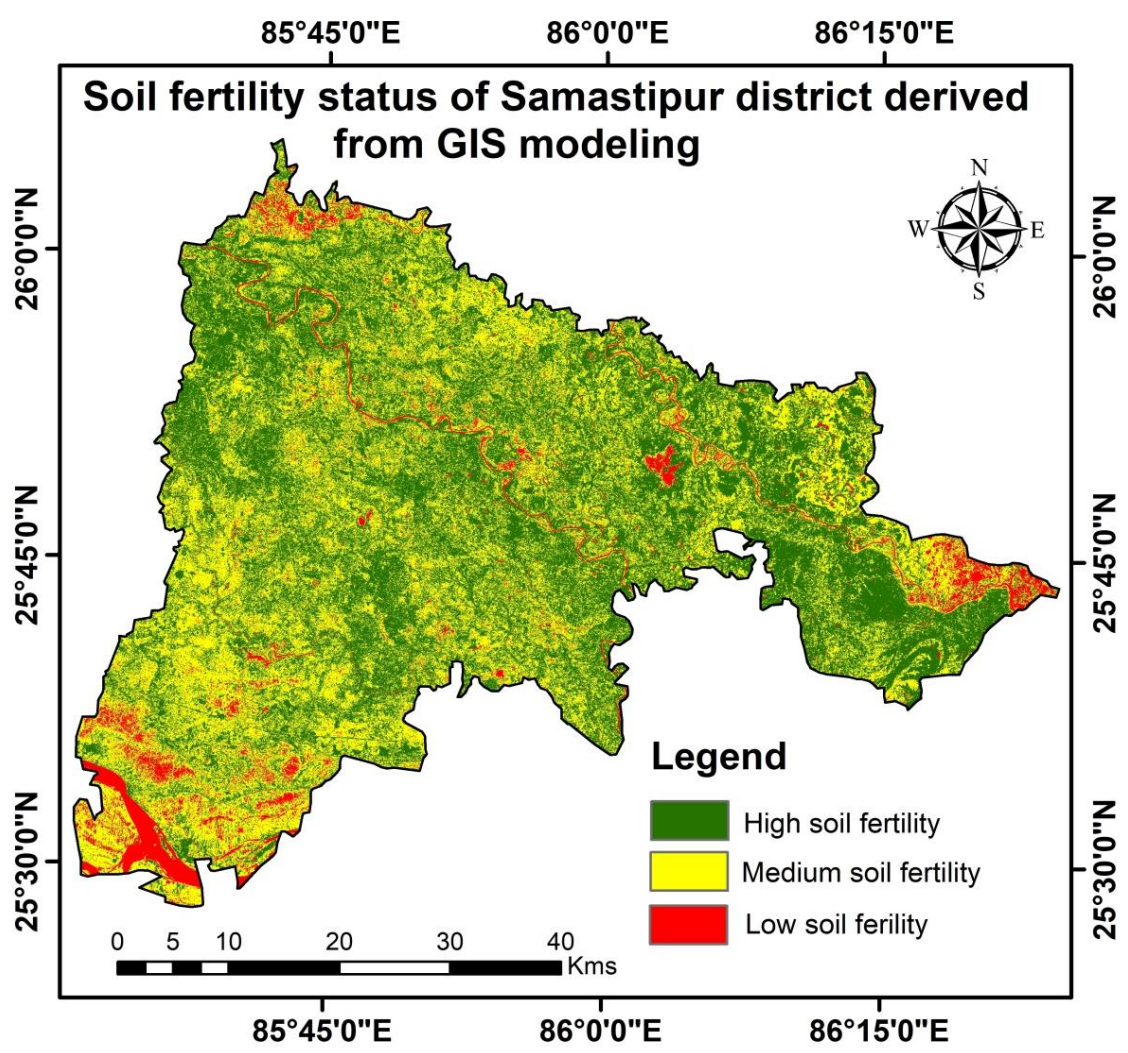

Fig.3. Soil fertility status map of Samastipur district

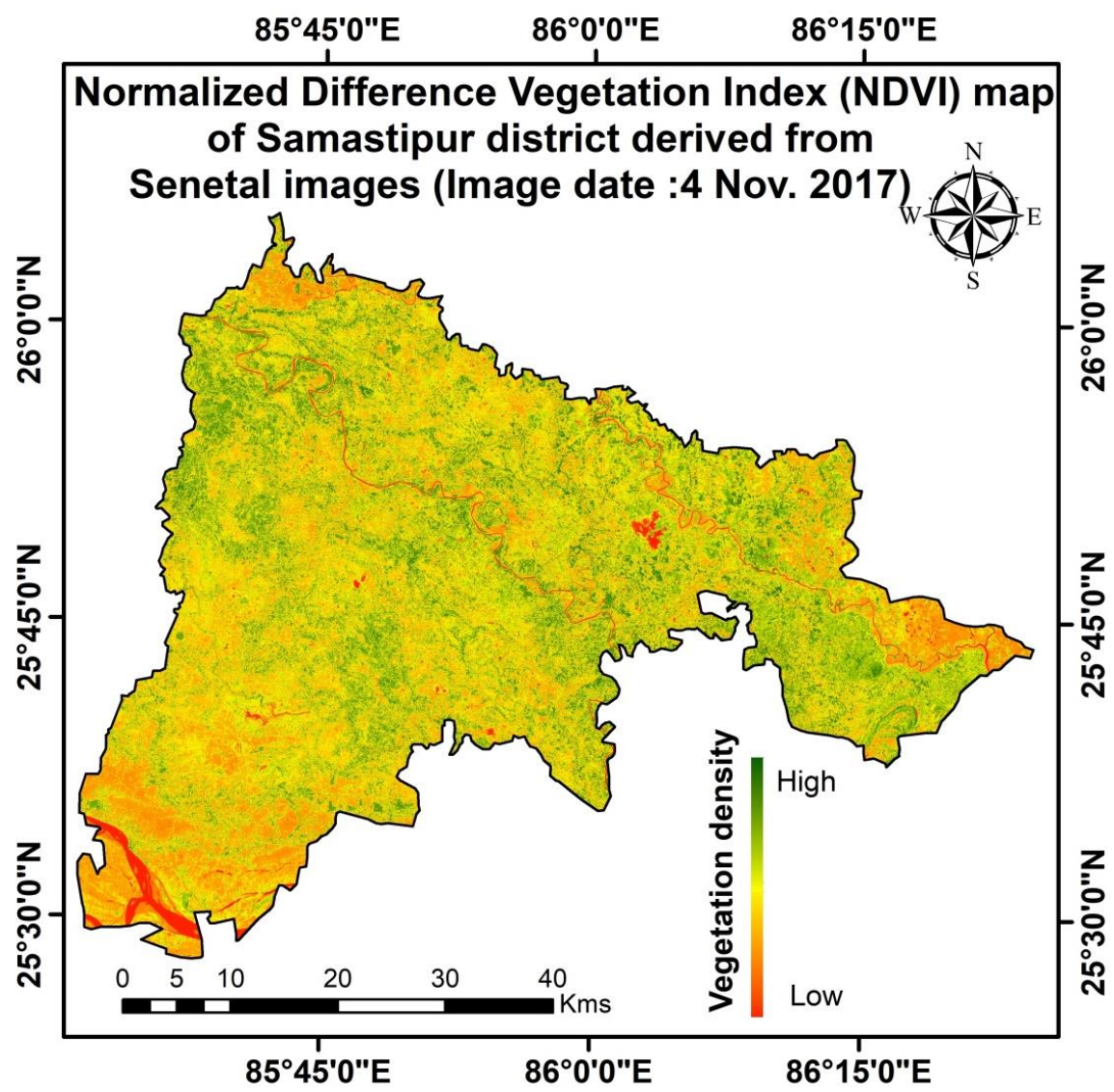

Fig.4. NDVI map of Samastipur district 
equal weight to their themes for evaluating the land for agroforestry purpose.

\section{NDVI map}

The Normalized Difference Vegetation Index (NDVI) is widely used vegetation index which significantly reflects the vegetation health and vigour from remote sensing data (Gomes et al. 2017) and can be successfully used as one of the parameters for agroforestry suitability mapping (Ahmad et al. 2018a). NDVI map produced from Senetal datasets were used in this study is given in figure 4. NDVI datasets are quite common and significantly used for modeling and determining the spatial patterns (Lopresti et al. 2015). Furthermore, it is used to determine the relationship between NDVI values and vegetation density. The high value of NDVI reflects the lesser the erosion extent due to high vegetation vigour (Rey 2003; Duran et al. 2008).

Generation of slope maps from digital elevation model

The Digital Elevation Model (ASTER) datasets were used for generating slope map (Figure 5). ASTER data and its topographical products are suitably utilized in diversified applications including modeling in Agroforestry suitability mapping (Ahmad and Goparaju 2017b).

\section{Wetness map}

The Landsat -8 data was used for determining the wetness by converting the actual image data into reflectance (https://landsat.usgs.gov/ landsat-8-18-data-users-handbook-section-5) and further processed for determining the wetness utilizing the Baig et al. 2014 methodology (Ahmad et al. 2017a). The wetness map generated is given in figure 6 .

\section{Land use/ land cover (LULC) map}

The Senetal satellite datasets were used and various land use land cover categories were delineated using the supervised classification methods by providing signatures of different land use categories (Ahmad et al. 2018b). Supervised classification is an approach widely used for the quantitative analysis of remote sensing image data using the concept of segmenting the spectral domain into regions (Richards, 2013). The various land use land cover categories such as trees, tree mixed, agriculture, settlement, water and open area were delineated which is given in figure 7.

Agroforestry suitability mapping using GIS modeling

The benefits of GIS are that; each GIS layer can be visualized which shows the spatial distribution pattern/information whereas GIS can integrate digital maps derived from diversified source. GIS offer spatial modeling (Burrough 1986) can be utilized for agroforestry (Ahmad et al. 2017 b) by pool different thematic layers (Ahmad and Goparaju, 2017a) with their weightages/ranks as per their importance (Figure 8; Table 2). The weight of each thematic layers has been calculated which is given in table 2 based on pairwise comparison (Ahmad et al. 2018c) widely used in the scientific study. Pairwise comparison is a procedure of comparing various entities/units in pairs to decide which of each entity/units is preferred, or has a greater amount of some quantitative property, or whether or not the two entities are alike (Furnkranz \& Hullermeier, 2010; 2011)

The weighted raster was finally classified into four agroforestry suitability groups (very high suitability, high suitability, moderate suitability and low suitability) are given in figure 9. Similar methodological approach and weightages have been assigned by Ahmad et al. 2018 a, b for identifying the land potentiality/ suitability for agroforestry. 


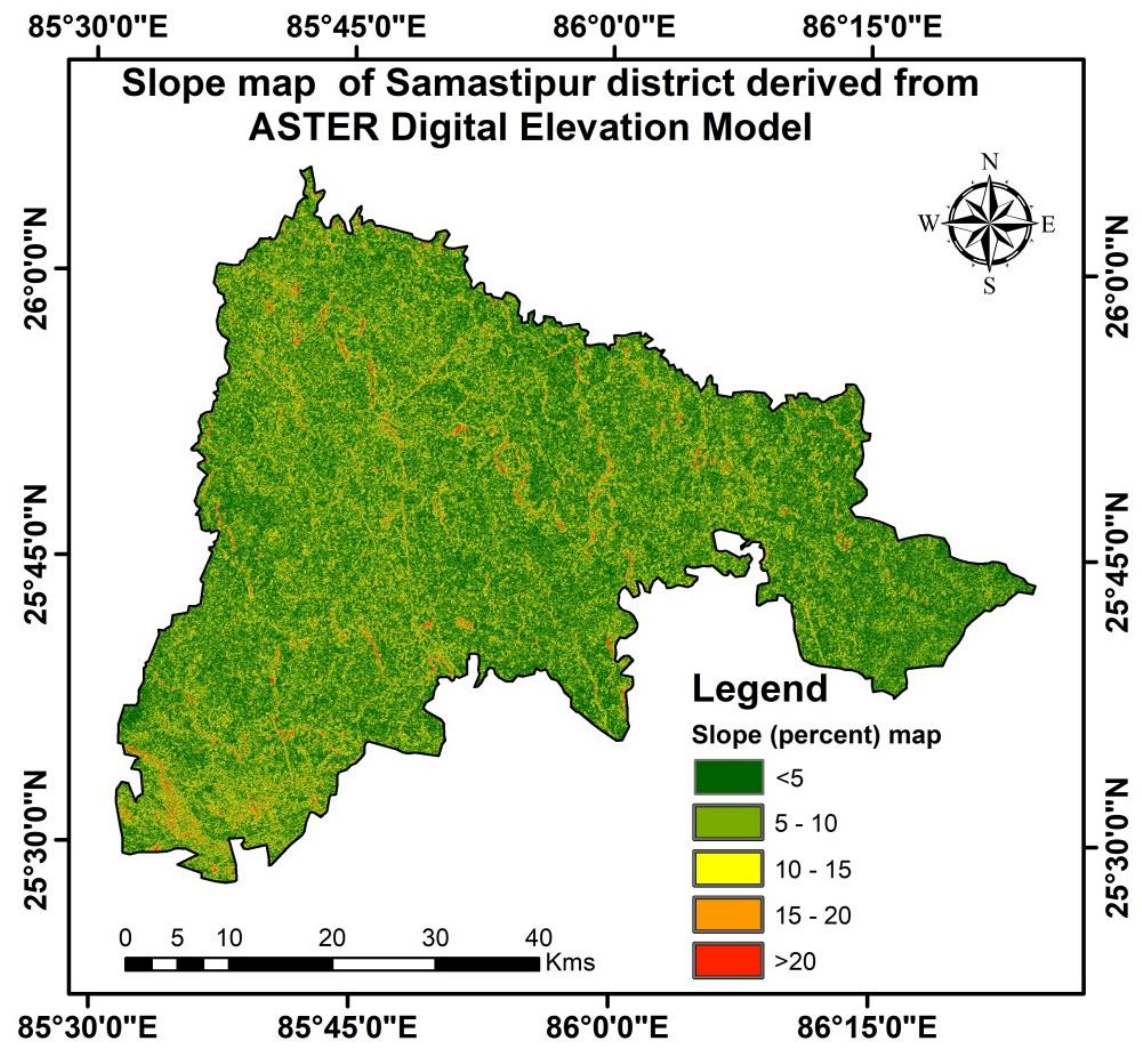

Fig.5. Slope map of Samastipur district

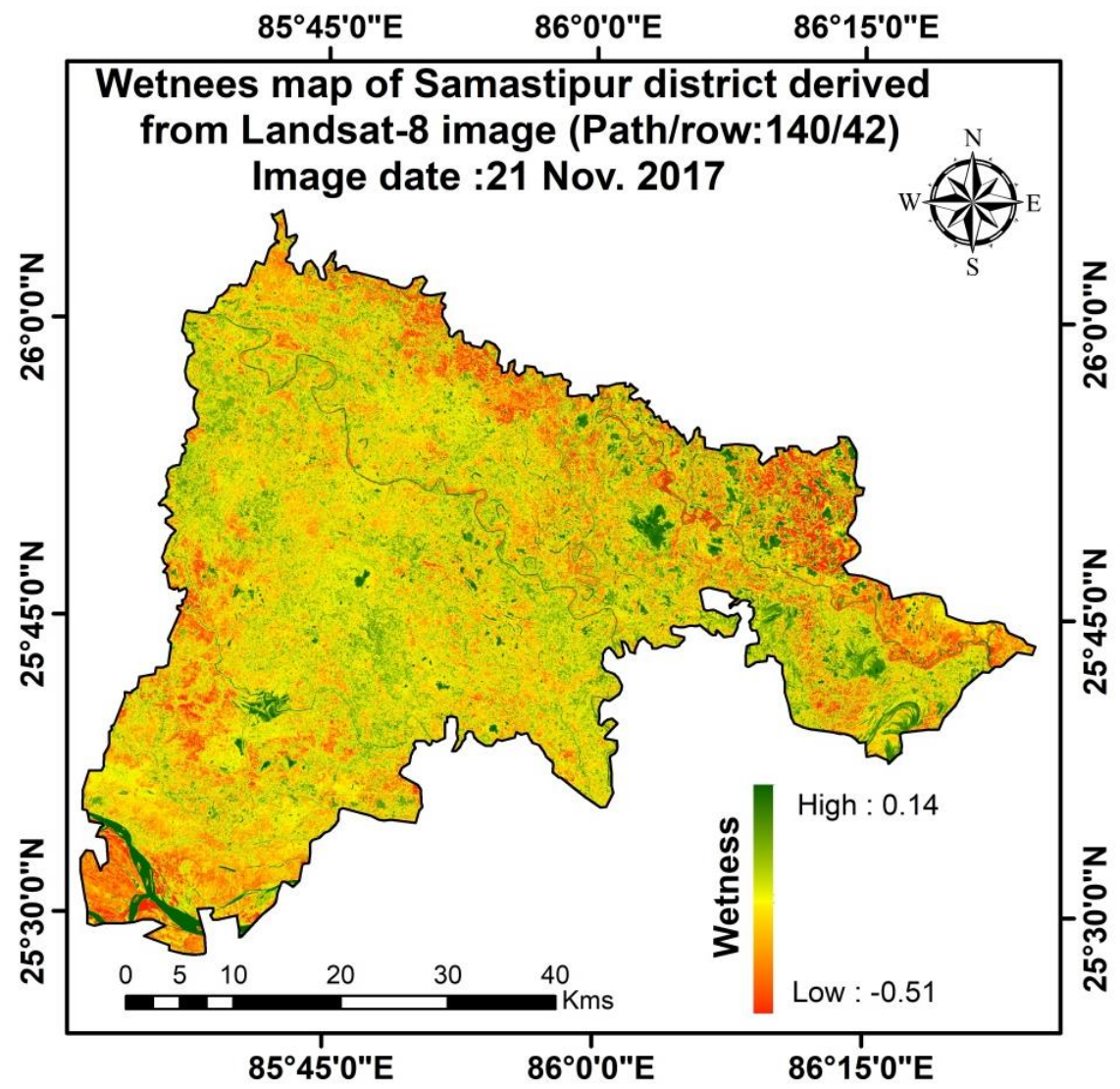

Fig.6. Wetness map of Samastipur district 


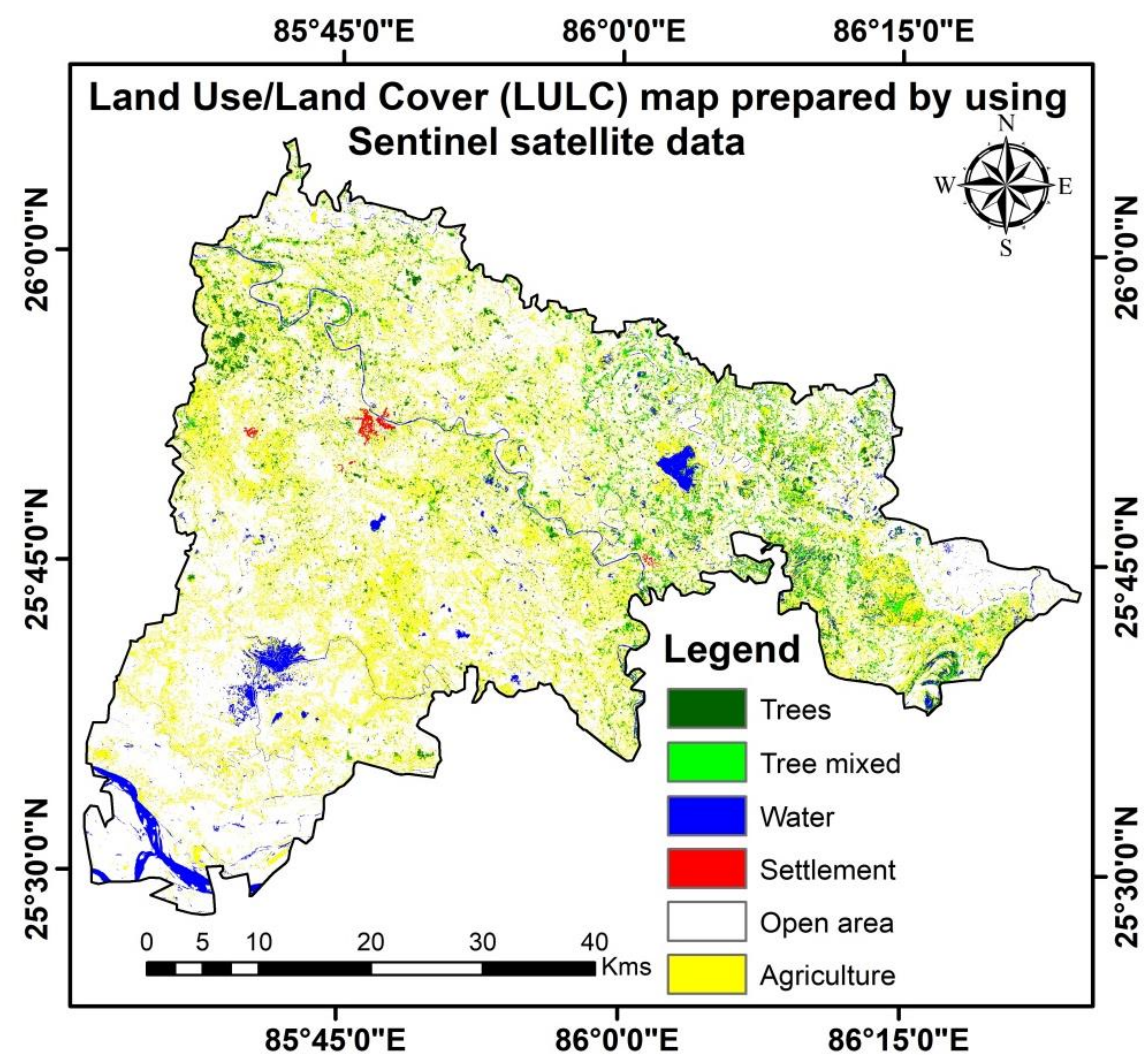

Fig.7. Land use/ land cover (LULC) map of Samastipur district

Tab.2. Weight factors/ranks for determining Agroforestry suitability mapping

\begin{tabular}{ccccl}
\hline $\begin{array}{c}\text { Agroforestry suitability } \\
\text { mapping }\end{array}$ & Weights \% & Value/Description & Ranks & Suitability \\
\hline Soil fertility status & 45.8 & Three categories based & 3 & $\begin{array}{l}\text { High } \\
\text { Medium } \\
\text { on weighted average output }\end{array}$ \\
& & 2 & 1 & Low \\
\hline Slope & 17.2 & $<5$ & 3 & High \\
& & $5-15$ & 2 & Medium \\
& 22.6 & $>15$ & 1 & Low \\
\hline Wetness factor & & $<-0.29$ & 1 & Low \\
& & $(-0.29)-(-0.06)$ & 2 & Medium \\
& 14.4 & $<(-0.06)$ & 3 & High \\
\hline NDVI & & $0.2-0.5$ & 1 & Low \\
& & $>0.5$ & 2 & Medium \\
\hline
\end{tabular}

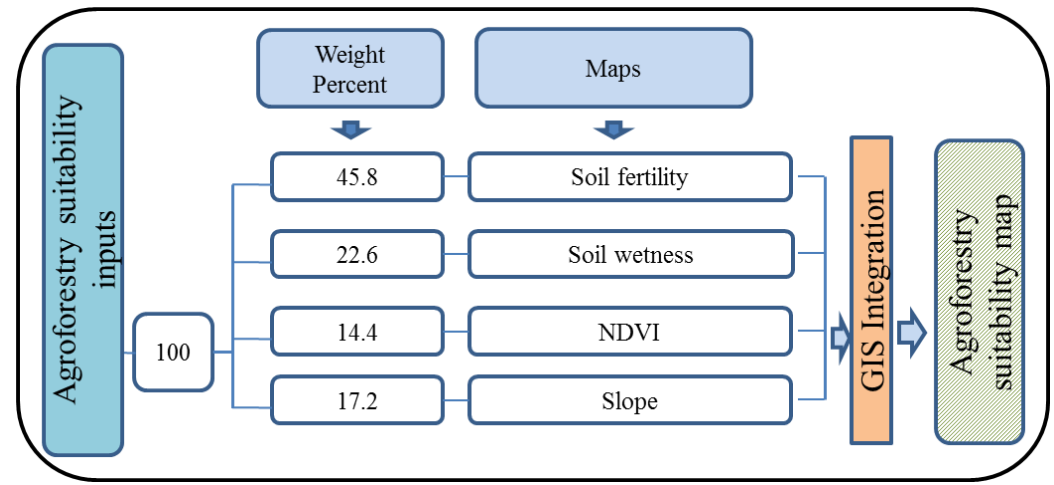

Fig.8. GIS Integration and modeling for Agroforestry suitability map 


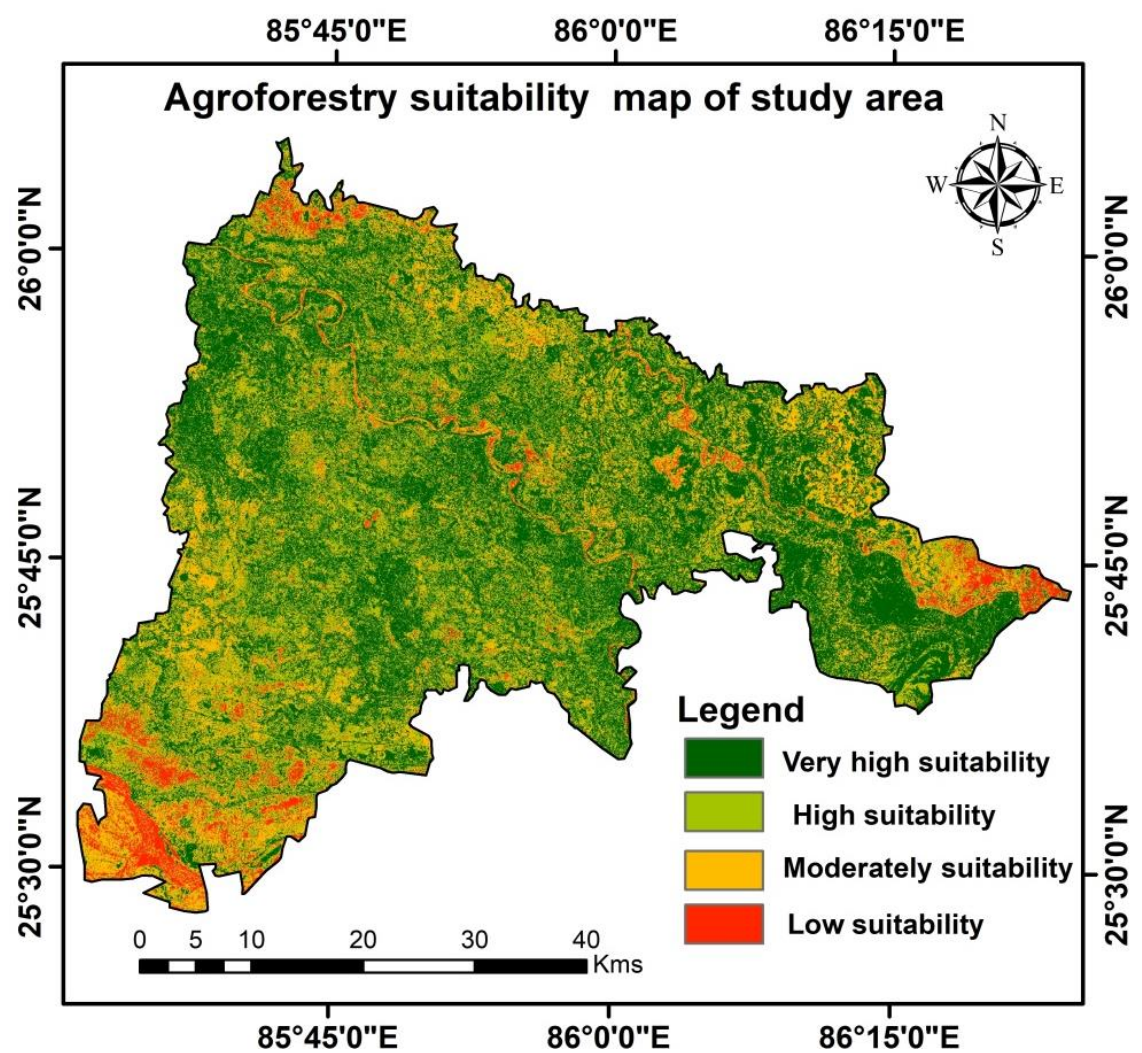

Fig.9. Agroforestry suitability map of Samastipur district

\section{Results and Discussion}

\section{Agroforestry suitability mapping}

Agroforestry suitability maps were generated for the Samastipur district of Bihar, India which showed $48.22 \%$ as very high suitable, $22.83 \%$ high suitable, $23.32 \%$ moderate suitable and 5.63\% low suitable (Table 3; Figure 9). The lands suitable for agroforestry are found more nearer to river/ in lowland areas because of their high soil fertility and abundant soil wetness whereas in south western part of the study areas were less suitable to agroforestry because of the soil exhibit low to medium soil fertility and low wetness (Figure 3\& Figure 6) Similar finding has been observed by Ahmad et al. 2017b. The various agroforestry systems such as Agri-hortisilviculture, Agri-silviculture, silvi-pastoral and agro-silvi-pastoral can be significantly applied seeing the site condition of land. The tree species such as Albizia procera, Butea monosperma, Syzygium cumini, Terminalia arjuna and Anthocephalus cadamba can be grown in waterlogged area whereas Dalbergia sissoo, Gmelina arborea Madhuca indica, Albizia lebbeck, Ziziphus jujuba and Acacia catechu can be grown in unfertile land. Furthermore, tree species such as Azadirachta indica, Pongamia pinnata, Terminalia arjuna, Albizia procera, Albizia lebbeck and Acacia auriculiformis can be grown in alkaline soil. The multipurpose leguminous tree species can be raised in field bunds to enhance the soil fertility of land (Nair 1985).

Tab.3. Agro forestry suitability of study area with area statistics

\begin{tabular}{ccc}
\hline $\begin{array}{c}\text { Agro forestry } \\
\text { suitability }\end{array}$ & $\begin{array}{c}\text { Area in } \\
\text { square } \\
\text { kilometer }\end{array}$ & Percentage \\
\hline $\begin{array}{c}\text { Very highly } \\
\text { suitable }\end{array}$ & 1400.17 & 48.22 \\
\hline High suitable & 662.88 & 22.83 \\
\hline $\begin{array}{c}\text { Moderate } \\
\text { suitable }\end{array}$ & 677.31 & 23.32 \\
\hline Low suitable & 163.64 & 5.63 \\
\hline
\end{tabular}


Agroforestry suitability Vs. Land use/land covers (LULC)

Here we have examined the land use/land cover of the study area and compared it with various agroforestry suitability classes (Table 4). The total area percent of LULC categories such as trees and tree mixed area were found to be approximately $6.4 \%$ of the total geographical area. Furthermore, the total agriculture (especially rabi crop) and open area percent were found to be approximately $24.7 \%$ and $65.3 \%$ of total geographical area respectively. The cross evaluation of these area with agroforestry suitability reveals $86.4 \%$ (agriculture) and 30.2\% (open area) of land falls into very high agroforestry suitable. This data revealed that there is huge potentiality to harness agroforestry practices in the above mentioned categories if utilized scientifically. The open area land usually suffers with some limitation such as soil fertility, soil moisture and land erosion. Such limitation can be overcome by utilizing adequate fund/technology (supported by government) because most of the farmers/land owners in these areas are with poor socio economic condition.

\section{Agroforestry suitability in climate change scenario}

Agriculture and trees play an important role in the rural economy of India, by providing diversified jobs for large population. Most of the poor people in Bihar live in rural areas, majority of them depend upon agriculture practices for their livelihood which is threatened due to climate severity. The climate change leads to more climate anomalies such as increase in mean annual temperature, more frequent drought, severe heat waves and frequent floods. These weather events together will have the adverse impact on agriculture in future is a serious policy concern.

We have predicted the annual temperature of Kharif and rabi season using the RCP 6 simulation model for the year 2050 are given in figure 10 and figure 11 respectively. The maps showed that the temperature increase in the year 2050 will be with the range of $1.13{ }^{\circ} \mathrm{C}$ to 1.29 ${ }^{\circ} \mathrm{C}$ during kharif and rabi season. In each degree-Celsius increase in mean temperature would, on average will decrease the yields of rice by $3.2 \%$, maize by $7.4 \%$, wheat yield by $6 \%$ and soybean by $3.1 \%$ (Zhao et al. 2017).

\section{Conclusion}

This study utilized the spatial themes from the diverse sources of information which have significant relation to agroforestry suitability and scientifically integrated/modeled in GIS domain. Computer based scientific evaluation of various datasets and its logical analysis in GIS with complex cross evaluation queries greatly supports the decision-making process. The people of Bihar are largely dependent on agriculture therefore adopting the agroforestry by them will significantly achieve sustainability in agriculture and allied sector while optimizing the land productivity in shifting climate change scenario.

Agroforestry is seen as an extremely useful solution which can sustain the extreme weather events and simultaneously fulfill the demand for food, fodder, nutrition, energy, employment and can protect our fragile environment. Bihar state is going to launch new agroforestry policy (PTI, 2018). Our research of agroforestry suitability mapping will greatly help the agroforestry policy makers of Bihar for extending it in new area. There are significantly large numbers of Agriculture University in Bihar including the Dr. Rajendra Prasad Central Agricultural University who are engaged in various agroforestry research works. Such analysis/results provide the huge scope to harness agroforestry practice in agriculture and open area land which showed significantly very high agroforestry suitability. The temperature prediction during kharif and rabi season for the year 2050 also revealed significant increase in 


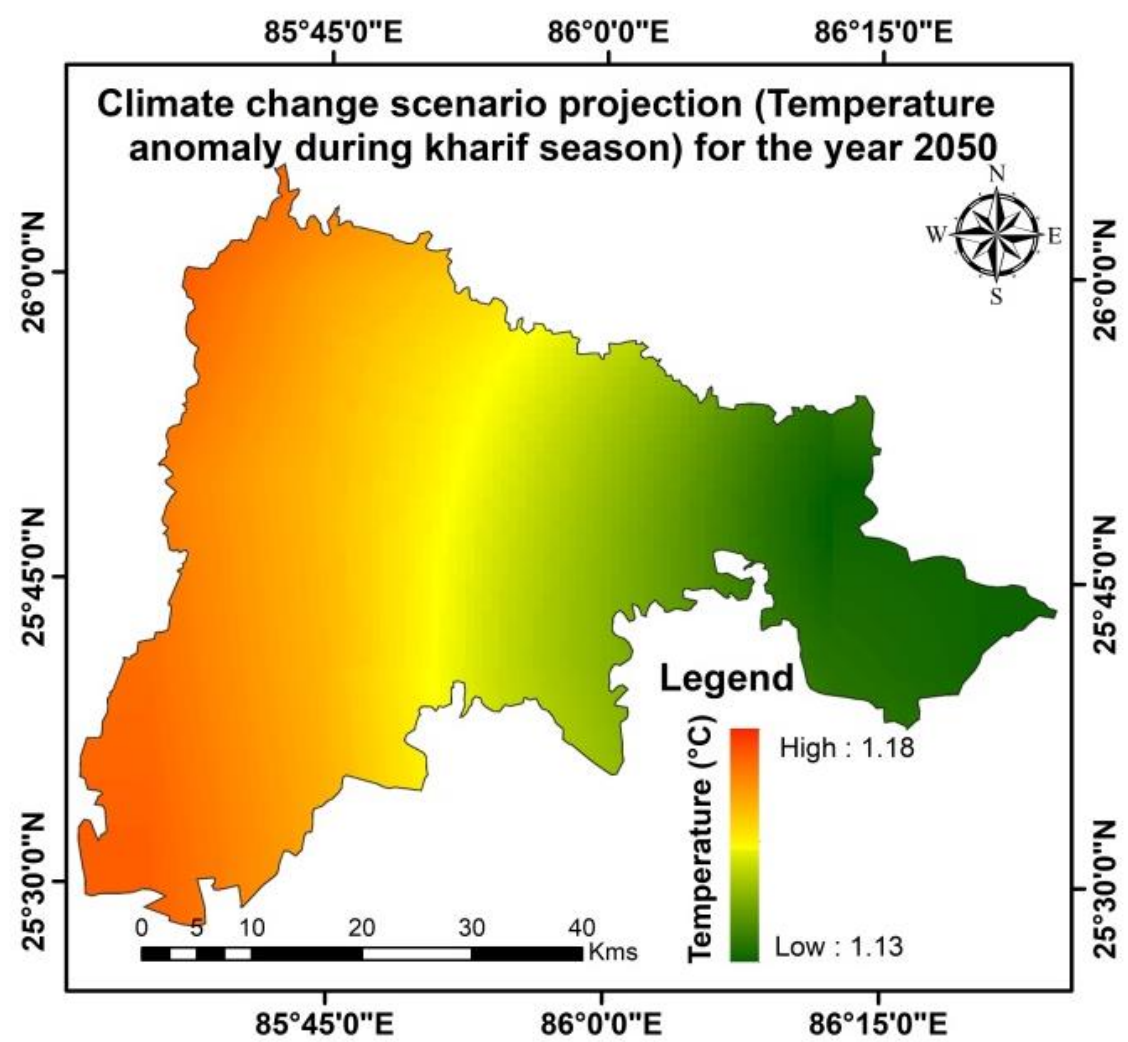

Fig.10. Temperature anomaly during kharif season in Samastipur district

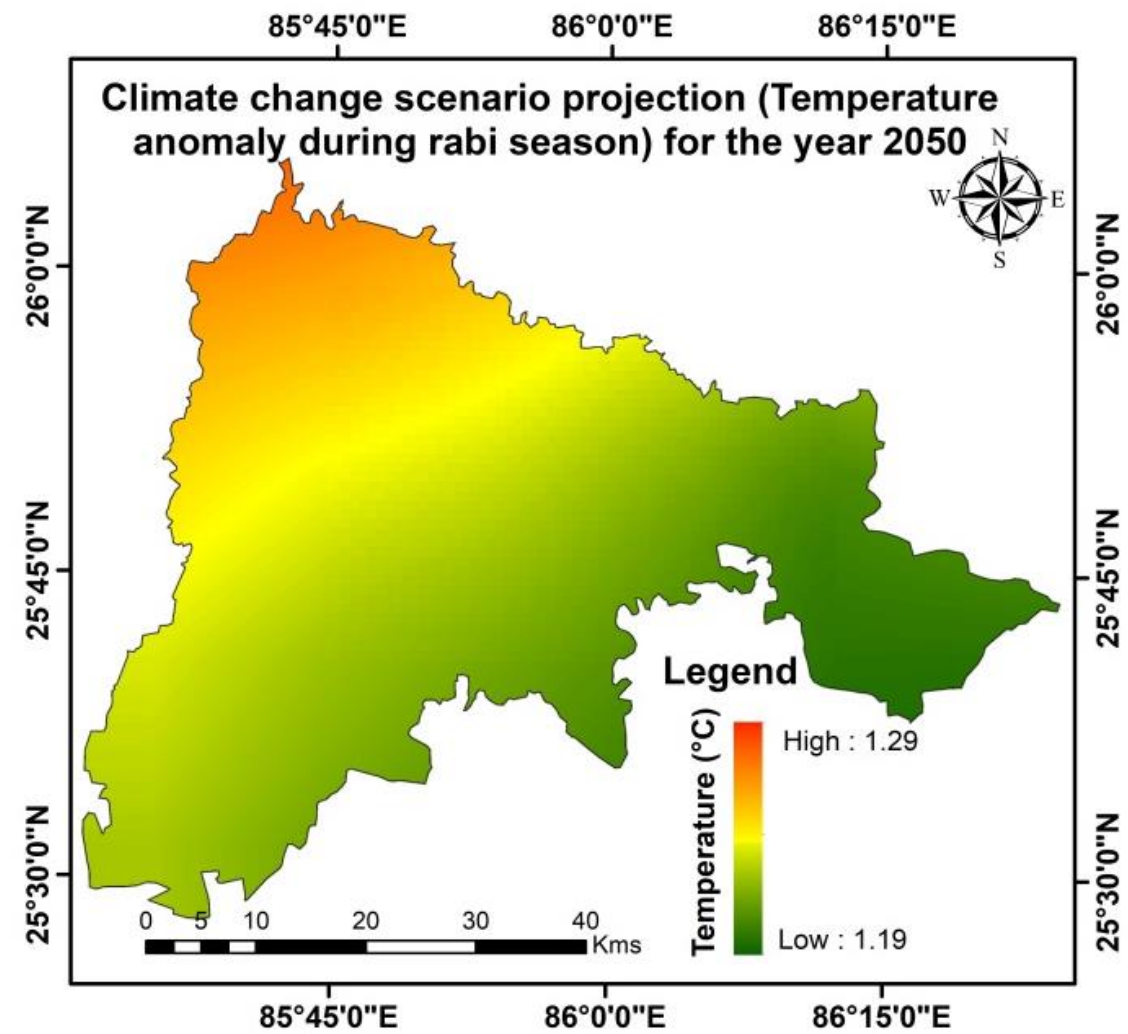

Fig.11. Temperature anomaly during rabi season in Samastipur district 
Tab4. Agroforestry suitability vs. Land Use/Land cover

\begin{tabular}{lccccc}
\hline \multirow{2}{*}{ LULC types } & \multicolumn{5}{c}{ Land Use/Land cover area vrs Agroforestry suitability area in $\mathbf{k m}^{\mathbf{2}}$} \\
\cline { 2 - 6 } & \multicolumn{5}{c}{ Agroforestry suitability } \\
\cline { 2 - 6 } & Low & Moderate & High & Very high & Grand Total in $\mathbf{k m}^{\mathbf{2}} \mathbf{( \% )}$ \\
\hline Trees & 0.12 & 0.64 & 3.19 & 92.82 & $96.78(3.33)$ \\
Tree mix & 0.09 & 0.57 & 3.05 & 84.84 & $88.56(3.05)$ \\
Water & 26.45 & 25.97 & 18.08 & 27.88 & $98.38(3.39)$ \\
Settlement & 0.38 & 1.70 & 1.55 & 1.06 & $4.70(0.16)$ \\
Open area & 135.61 & 626.97 & 561.95 & 572.61 & $1897.13(65.33)$ \\
Agriculture & 0.94 & 21.40 & 75.08 & 621.02 & $718.45(24.74)$ \\
Grand Total & 1400.17 & 662.88 & 677.31 & 163.64 & 2904 \\
in $\mathbf{~ k m}^{\mathbf{2}} \mathbf{( \% )}$ & $(48.22)$ & $(22.83)$ & $(23.32)$ & $(5.63)$ & $(100)$ \\
\hline
\end{tabular}

temperature in future which will impact adversely the crop production.

Present research has its own importance because such agroforestry suitability mapping has been done first time in the state of Bihar using Remote Sensing and GIS. This research showed the ability of Remote Sensing, GIS as well as integrating the themes using the concept of modeling by pooling the various layers of land, soil and topographical datasets.

\section{Future research scope}

There is a need to replicate such work at district levels and state level which are a potential research gap in the state of Bihar.

\section{Acknowledgement}

The authors are grateful to the USGS, European Commission's science and knowledge service, National Center for Atmospheric Research and DIVA GIS for providing free download of various dataset used in the analysis.

\section{References}

Ahmad, F. \& Goparaju, L. (2017a) Geospatial approach for Agroforestry Suitability mapping: To Enhance Livelihood and Reduce Poverty, FAO based documented procedure (Case study of Dumka district,
Jharkhand, India). Biosci Biotechnol Res Asia 14: 651-665. doi : http://dx.doi.org/10.13005/bbra/2491

Ahmad, F.\& Goparaju, L. (2017b) Land Evaluation in terms of Agroforestry Suitability, an approach to Improve Livelihood and Reduce Poverty: A FAO Based Methodology A Geospatial Solution: A case study of Palamu district, Jharkhand, India. Ecological Questions 25: 67-84. doi: http://dx.doi.org/10.12775/EQ.2017.006

Ahmad, F., Goparaju, L. \& Qayum, A. (2017a) Agroforestry suitability analysis based upon nutrient availability mapping: a GIS based suitability mapping. AIMS Agriculture and Food 2(2): 201-220. doi: 10.3934/agrfood.2017.2.201

Ahmad, F., Goparaju, L.\& Qayum, A.(2017b) FAO guidelines and geospatial application for agroforestry suitability mapping: case study of Ranchi, Jharkhand state of India. Agroforest Syst https://doi.org/10.1007/s10457-017-0145-y

Ahmad, F., Goparaju, L.\& Qayum, A.(2018c) Wild life habitat suitability and conservation hotspot mapping: Remote Sensing and GIS based decision support system. AIMS Geosciences, 4(1): 66-87. doi: 10.3934/geosci.2018.1.66.

Ahmad, F., Uddin, M.M. \& Goparaju, L. (2018a) Agroforestry suitability mapping of India: geospatial approach based on FAO 
guidelines Agroforest Syst https://doi.org/10.1007/s10457-018-0233-7 Ahmad, F., Uddin, M.M. \& Goparaju, L. (2018b) Geospatial application for agroforestry suitability mapping based on FAO guideline: case study of Lohardaga, Jharkhand State of India Spat. Inf. Res. https://doi.org/10.1007/s41324-018-0194-y

Baig, M.H.A., Zhang, L., Shuai, T.,Tong, Q.(2014). Derivation of a tasselled cap transformation based on Landsat 8 atsatellite reflectance.Remote Sensing Letters5(5): $\quad$ 423-431. doi:10.1080/2150704X.2014.915434

Burrough, P.A. (1986) Principles of Geographic Information Systems for Land Resource Assessment. Monographs on Soil and Resources Survey No. 12, Oxford Science Publications, New York.

Chen, Q., Lu, D. Keller, M. dos-Santos, M. N. Bolfe, E. L. Feng, Y. \& Wang. C. (2016) "Modeling and Mapping Agroforestry Aboveground Biomass in the Brazilian Amazon Using Airborne Lidar Data." $\begin{array}{lll}\text { Remote } \quad \text { Sensing } & 8 & \text { (1):21. }\end{array}$ doi:10.3390/rs8010021.

Dash, S.K., Jenamani, R.K., Kalsi, S.R.\& Panda, S.K. (2007) Some evidence of climate change in twentieth-century India. Climatic Change 85:299-321.

Duran, Z.V.H., Rodriguez, P.C.R., Francia, M.J.R., Carceles, R.B., Martinez, R.A. \& Perez, G.P. (2008) Harvest intensity of aromatic shrubs vs. soil-erosion: an equilibrium for sustainable agriculture (SE Spain), Catena 73(1):107-116.

Ellis, E.A., Bentrup, G.\& Schoeneberger, M.M. (2004) Computer-based tools for decision support in agroforestry: current state and future needs. Agro for Syst 61(1):401-421.

Ellis, E.A., Nair, P.K., Linehan, P.E., Beck, H.W.\& Blanche, C.A. (2000) A GIS-based database management application for agroforestry planning and tree selection. Computers and Electronics in Agriculture 27:41-55.
Furnkranz, J., \& Hullermeier, E. (2010). Preference learning and ranking by pairwise comparison. In J. Fürnkranz \& E. Hüllermeier (Eds.), Preference learning (pp. 65-82). Berlin: Springer.

Furnkranz, J., \& Hullermeier, E. (2011). Preference learning: an introduction. In J. Fürnkranz \& E. Hüllermeier (Eds.), Preference learning (pp. 1-17). Berlin: Springer.

Glantz, M.H., Gommes, R. and Ramasamy, S. (2009) Coping with a changing climate: considerations for adaptation and mitigation in agriculture. http://www.fao.org/docrep /012/i1315e/i1315e.pdf

Gomes, A.C.C., Bernardo, N. \& Alcantara, E. (2017) Accessing the southeastern Brazil 2014 drought severity on the vegetation health by satellite image. Nat Hazards 89: 1401. https://doi.org/10.1007/s11069-0173029-6

Goswami, B.N., Venugopal, V., Sengupta, D., Madhusoodanam, M.S., \& Xavier, P.K. (2006) Increasing trends of extreme rain events over India in a warming environment. Science 314: 1442-1445.

Hatfield JL, Prueger JH (2015) Temperature extremes: effect on plant growth and development. Weather Clim Extrem 10:410. doi: 10.1016/j.wace.2015.08.001

Inman, M. (2011) Opening the future. Nature Climate Change, 1: 7-9. doi:10.1038/nclimate 1058

ICRAF (1993) International Centre for Research in Agroforestry: Annual Report 1993. Nairobi, Kenya. pp 208.

Lal, M. (2003) Global climate change: India's monsoon and its variability. Journal of Environmental Studies \& Policy 6: 1-34.

Lal, M., Cubasch, U., Voss, R. \& Waszkewitz, J. (1995) Effect of transient increases in greenhouse gases and sulphate aerosols on monsoon climate. Current Sci. 69(9), 752763.

Lopresti, M.F., Di Bella, C.M. \& Degioanni, A.J. (2015) Relationship between MODIS- 
NDVI data and wheat yield: A case study in Northern Buenos Aires province, Argentina. Inf. Process. Agric. 2015, 2, $73-$ 84

https://doi.org/10.1016/j.inpa.2015.06.001

Miyan, M.A. (2015) Droughts in Asian least developed countries: Vulnerability and sustainability. Weather Clim. Extremes 7:823.

Nair, P.K.R. (1985) Classification of agroforestry systems. Agroforest Syst 3(2): 97-128.

https://doi.org/10.1007/BF00122638

NAP (2014) National Agroforestry Policy http://www.indiaenvironmentportal.org.in/f iles/file/Agroforestry\%20policy\%202014.p df (Accessed on $14^{\text {th }}$ September 2018).

Newaj, R., Chavan, S.B. \& Prasad, R. (2015) Climate-smart agriculture with special reference to agroforestry. Indian $\mathrm{J}$. of Agroforestry 17(1): 96-108

NCAR GIS Program. (2012) Climate Change Scenarios, version 2.0. Community Climate System Model, June 2004 version 3.0. http://www.cesm.ucar.edu/models/ccsm3.0 / was used to derive data products. NCAR/UCAR.

URL:

http://www.gisclimatechange.org.

(Accessed on $5^{\text {th }}$ March 2018)

PTI (2018) Bihar to have policy for agroforestry:

Nitish,

(https://www.business-

standard.com/article/pti-stories/bihar-to-

have-policy-for-agroforestry-nitish-

118021301374_1.html) accessed on $23^{\text {rd }}$ June 2018.

Ramanathan, V., Chung, C., Kim, D., Bettge, T., Buja, L., Kiehl, J.T., Washington, W.M., Fu, Q., Sikka, D.R. \& Wild, M. Atmospheric brown clouds: impacts on South Asian climate and hydrological cycle. Proceedings of National Academy of Sciences of the United States of America. 2005; 102:5326-5333.

Reisner, Y., de Filippi, R., Herzog, F. et al. (2007) Target regions for silvoarable agroforestry in Europe. Ecol Eng 29: 401418. doi:10.1016/j.ecoleng.2006.09.020

Rey, F. (2003) Influence of vegetation distribution on sediment yield in forested marly gullies. Catena 50: 549-562.

Richards J.A. (2013) Supervised Classification Techniques. In: Remote Sensing Digital Image Analysis. Springer, Berlin, Heidelberg. https://doi.org/10.1007/978-3642-30062-2_8

Ritung, S, Wahyunto, Agus F. \& Hidayat, H. (2007) Land Suitability Evaluation with a case map of Aceh Barat District. Indonesian Soil Research Institute and World Agroforestry Centre, Bogor, Indonesia. ISBN: 979-3198-36-1

Sinha Ray, K. C. \& De, U. S. (2003) Climate change in India as evidenced from instrumental records. WMO Bulletin 2(1), 53-59.

Torquebiau, E (2013) Agroforestry and climate change.

http://www.fao.org/climatechange/361100dff1bd456fb39dbcf4d3b211af5684e2.pdf (Accessed on $5^{\text {th }}$ March 2018)

Zhao, C., Liu, B., Piao, S. et al. (2017).Temperature increase reduces global yields of major crops in four independent estimates. Proc. Natl. Acad. Sci.114(35):9326-9331. https://doi.org/10.1073/pnas.1701762114

Zhou,S., Zhou,W., Lin,G., Chen,J., Jiang,T \& Li.M. (2017) "Adapting to climate change: scenario analysis of grain production in China", China Agricultural Economic Review, Vol. 9 Issue: 4, pp.643-659, https://doi.org/10.1108/CAER-10-2016$\underline{0173}$

Zomer, R.J., Trabucco, A., Coe, R.\& Place, F. (2009) Trees on Farms: Analysis of the Global Extent and Geographical Patterns of Agroforestry; ICRAF Working Paper No. 89; World Agroforestry Centre: Nairobi, Kenya. 